\title{
Exploring the Impact of Permitting and Local Regulatory Processes on Residential Solar Prices in the United States
}

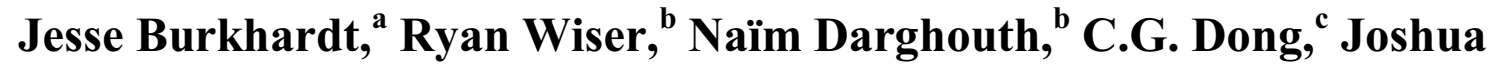 \\ Huneycutt ${ }^{d}$ \\ ${ }^{a}$ Yale University, 205 Prospect St., New Haven, CT 06511 (USA) \\ ${ }^{\mathrm{b}}$ Ernest Orlando Lawrence Berkeley National Laboratory, 1 Cyclotron Road, Berkeley, CA 94720 (USA) \\ ' University of Texas at Austin, 2315 Red River St., Austin, TX 78712 (USA) \\ d U.S. Department of Energy, 1000 Independence Ave, SW, Washington, DC 20585 (USA)
}

\section{Corresponding Authors}

Ryan Wiser, Berkeley Lab, rhwiser@lbl.gov +1 (510)-486-5474

Naïm Darghouth, Berkeley Lab, ndarghouth@lbl.gov +1 (510)-486-4570

Jesse Burkhardt, Yale University, jesse.burkhardt@yale.edu +1 (503)-312-8943

Abstract: This article statistically isolates the impacts of city-level permitting and other local regulatory processes on residential PV prices in the U.S. We combine data from two "scoring" mechanisms that independently capture local regulatory process efficiency with the largest dataset of installed PV prices in the United States. We find that variations in local permitting procedures can lead to differences in average residential PV prices of approximately $\$ 0.18 / \mathrm{W}$ between the jurisdictions with the leastfavorable and most-favorable permitting procedures. Between jurisdictions with scores across the middle $90 \%$ of the range (i.e., 5 th percentile to 95 th percentile), the difference is $\$ 0.14 / \mathrm{W}$, equivalent to a $\$ 700(2.2 \%)$ difference in system costs for 
a typical 5-kW residential PV installation. When considering variations not only in permitting practices, but also in other local regulatory procedures, price differences grow to $\$ 0.64-\$ 0.93 / \mathrm{W}$ between the least-favorable and most-favorable jurisdictions. Between jurisdictions with scores across the middle $90 \%$ of the range, the difference is equivalent to a price impact of at least $\$ 2500(8 \%)$ for a typical 5-kW residential PV installation. These results highlight the magnitude of cost reduction that might be expected from streamlining local regulatory regimes.

No table of figures entries found.Acronyms and Abbreviations

BIPV Building-integrated PV

DOE U.S. Department of Energy

HHI Herfindahl-Hirschman Index

LBNL Lawrence Berkeley National Laboratory

PII Permitting, inspection, and interconnection

PV Photovoltaic

RSC Rooftop Solar Challenge

TPO Third-party owned

TTS Tracking the Sun 


\section{Introduction}

Though still constituting a minor share of total electricity supply, solar photovoltaics (PV) have been deployed at a rapid pace in recent years. In 2013, $38 \mathrm{GW}$ of PV were installed globally, up from just $1.1 \mathrm{GW}$ installed 10 years earlier in 2004 (EPIA, 2014). The United States, as the world's third-largest market in 2013 , installed $4.8 \mathrm{GW}$, with significant new capacity in smaller household and larger commercial systems as well as in utility-scale applications (SEIA/GTM, 2014). This growth has been spurred by both government policy and system cost reductions (Shrimali and Jenner, 2013), with continued growth expected over the near and longer terms, especially within the context of combating global climate change (Baker et al., 2013; Edenhofer et al., 2011; IPCC, 2014).

For this growth to continue, given recent changes in the cost structure of PV systems, heightened emphasis is now being placed on reducing non-hardware "soft" costs. In particular, overall system-level PV cost reductions have been substantial in recent years (Barbose et al., 2014; Bazilian et al., 2013; Bolinger and Weaver, 2013; Branker et al., 2011; Candelise et al., 2013; Hernández-Moro and Martínez-Duart, 2013). However, in the United States at least, these system-cost reductions have been driven largely by hardware-cost reductions — specifically, a steep decline in the price of PV modules. Though learning-based reductions in soft costs are apparent on a longer-term basis (Schaeffer et al., 2004), soft costs have been somewhat stagnant in the United States, at least through 2012 (Barbose et al., 2014). As a result, for typical residential systems, soft costs represented $64 \%$ of total system costs in the United States in 2012 (Friedman et al., 2013). Moreover, these high soft costs are at least somewhat unique, as average residential PV prices in the United States remain well above those witnessed in many other 
major global PV markets (Barbose et al., 2013). Significant additional reductions in total installed costs, likely a precondition for continued rapid market growth, will therefore necessitate substantial progress in reducing soft costs.

This article focuses on one soft-cost element that has received a considerable amount of recent attention in the United States as potentially being partly responsible for the persistently high PV prices: local regulatory processes, including permitting, inspection, and interconnection (PII). A typical local regulatory process for PV may involve multiple local government departmental reviews (e.g., building, electrical, mechanical, plumbing, fire, structural, zoning, and aesthetic), a permitting fee and a site inspection, as well as interconnection-based reviews by the local utility. These processes are partially directed by state policies, but local governments and utilities are typically given wide latitude in how they are administered. Though the resulting procedures can help protect against unscrupulous or unskilled PV installers, the diversity of documentation requirements, application procedures, inspection processes, and fees complicates the PV market: approximately 18,000 different local "authorities having jurisdiction" exist in the United States, many of which have unique requirements. ${ }^{1}$

A variety of efforts is underway to not only document the procedures required in various jurisdictions, but also to streamline those procedures in order to reduce PV costs, especially in jurisdictions where procedures are particularly taxing. The U.S. Department of Energy's (DOE's) Rooftop Solar Challenge (RSC), for example, has funded teams of local and state

\footnotetext{
${ }^{1}$ These 18,000 authorities oversee roughly 42,000 unincorporated communities, some of which have their own requirements. Though we colloquially refer to "city-level" processes throughout much of this article, in fact, local procedures impacting PV are sometimes set by the county or by unincorporated jurisdictions. For the sake of consistency and ease of reading, however, and because most of the local procedures are in fact established by cities, throughout this paper we will use the terms "city" and "cities" to refer to loosely to "authorities having jurisdiction."
} 
governments along with utilities, installers, nongovernmental organizations, and others to reduce local administrative barriers to PV. ${ }^{2}$ As part of this effort, DOE has developed a scoring protocol for cities and applied it on two occasions. The nonprofit Vote Solar Initiative, meanwhile, created "Project Permit," which includes an online summary of city-level permitting requirements and scores cities based on those processes. ${ }^{3}$ The Solar America Board for Codes and Standards has developed an expedited permit process for PV (Brooks, 2012). Clean Power Finance has created an online database that compiles permitting requirements from around the nation; it is the data source for Vote Solar's Project Permit. ${ }^{4}$ Partly in response to these myriad efforts, a number of states have sought to streamline their local procedures (Stanfield et al., 2012).

In this article we statistically analyze the impact of these local, often city-level processes on the reported prices of residential PV systems. We use the unique city-level scores of these processes created by DOE through its RSC program and by Vote Solar through its Project Permit initiative. Our work leverages the sizable dataset of system-level PV prices managed by Lawrence Berkeley National Laboratory (LBNL) and is part of a larger body of research conducted by LBNL, Yale University, University of Wisconsin, and University of Texas at Austin that is exploring, more broadly, the drivers of PV price variability in the United States.

Our analysis helps to answer two key questions. First, to what degree are local regulatory processes in the United States impacting residential PV prices? Second, do the two different scoring mechanisms capture the idiosyncrasies of these local processes? Answers to these

2 See: http://www.energy.gov/eere/sunshot/rooftop-solar-challenge. 3 See: http://projectpermit.org/. 4 See: http://solarpermit.org/. 
questions can highlight the magnitude of cost reduction that might be expected from streamlining local regulatory regimes and, secondarily, may help refine city-level scoring methods.

We build on existing literature that has assessed these costs, and we seek to inform efforts that have sought to reduce them. Friedman et al. (2013) find that the national average cost of PII in the United States for residential systems in 2012 was $\$ 0.19 / \mathrm{W}$ ( $\$ 0.10 / \mathrm{W}$ for labor and $\$ 0.09 / \mathrm{W}$ for the permit fee). Seel et al. (2014) compare average PII costs in Germany and the United States for 2011, finding that German costs (at just $\$ 0.03 / \mathrm{W}$ ) were substantially lower than U.S. costs, on average. Ardani et al. (2013) identify a roadmap by which U.S. PII costs might approach German levels by 2020. SunRun (2011) finds that local permitting and inspection could cost $\$ 0.50 / \mathrm{W}$ in total for a typical residential installation. Tong (2012) estimates that the labor costs associated with permitting averaged $\$ 0.11 / \mathrm{W}$, with $36 \%$ of installers limiting or avoiding certain jurisdictions due to cumbersome processes. Dong and Wiser (2013) evaluate the heterogeneity in city-level permitting practices, finding that cities in California with the mostfavorable permitting practices had PV prices that were $\$ 0.27-\$ 0.77 / \mathrm{W}$ lower than cities with the least-favorable practices.

This previous work suggests that local regulatory processes can impact PV prices both directly, through administrative labor and fees imposed on PV installers, and indirectly, as economic rents accruing to installers because of barriers to market entry created by these processes. The impact of local regulatory procedures on the PV market exceeds the impact on PV prices alone, because these procedures may delay the completion of PV projects (Dong and Wiser, 2013) and can also limit participation in the market by both installers and potential PV customers (Tong, 2012). At the same time, there remains some uncertainty about the size of the average price impact and, more significantly, about the heterogeneity of those price effects across jurisdictions. 
Our work addresses the uncertainty in heterogeneity. In so doing, it builds on Dong and Wiser (2013), who conducted an econometric analysis of residential PV systems in California to explore the relationship between DOE RSC residential permitting scores and PV prices. We extend that work in several respects. First, we evaluate the impact of local processes using two third-party jurisdiction-level scoring systems, from the RSC and Vote Solar. Second, we extend the work both geographically and temporally. Whereas Dong and Wiser (2013) focus on RSC scores and PV installations in California in 2011 (44 cities, 3,000 PV installations), the present analysis uses RSC scores and PV installations for both 2011 and 2012, and we evaluate the impact of those scores across 13,904 PV systems within 73 cities and 6 states. The Vote Solar scores allow us to assess a much larger number of PV systems (43,551), cities (603), and states (11), adding to the richness of our dataset. Though the present work clearly does not cover all states and jurisdictions in the U.S., it does significantly expand on previous work and does cover a sizable fraction of the locations within which recent PV deployment has been most rapid. Third, Dong and Wiser (2013) focus solely on the "residential permitting score" from the RSC, which is just one aspect of the total score that DOE assigns to participating cities. In the present analysis, to capture local procedures that go beyond permitting, we use the city-level "total score" from the RSC. In so doing, we capture local variations in interconnection procedures, planning and zoning, financing options, and net-metering rules, in addition to permitting. Fourth, we are able to contrast loosely the RSC results with those that focus on the Vote Solar scores, which only cover permitting. Because the Vote Solar scoring mechanism emphasizes a smaller subset of the issues covered by the RSC scores, an analysis of both programs can illuminate how local procedures impact PV prices. Finally, while Dong and Wiser (2013) statistically controlled for a variety of other potential drivers of PV prices, the present analysis includes an even greater 
number of diverse control variables, reducing the chance of statistical bias and improving estimates of the impact of local regulatory procedures.

The remainder of the article is structured as follows. In Section 2, we discuss the data and methods used to conduct our analysis. In Section 3, we present and discuss the results. In Section 4, we draw conclusions and discuss policy implications.

\section{Methods}

This article combines data from the two independent city-level scores of local PV regulatory processes (DOE RSC and Vote Solar Project Permit) with data on PV prices, systems, and market characteristics from the largest dataset of PV installations in the United States. In this section, we discuss the PV price and other data used in our analysis, the two scoring methods, our final dataset, and our analytical methods.

This work leverages the largest dataset of PV system prices worldwide, used in LBNL's annual Tracking the Sun (TTS) report series (e.g., TTS VI: Barbose et al., 2013). The TTS VI data include reported PV system prices for more than 200,000 PV installations, representing 72\% of cumulative grid-connected PV capacity in the United States as of year-end 2012. The data were collected from $47 \mathrm{PV}$ incentive programs in 29 states and were subsequently cleaned and standardized to remove potential errors. ${ }^{5}$ In addition to system prices, the data also contain a variety of information about the PV installations - including date of installation; system size; geographical location; whether the system is residential, commercial, or other; and technology type (module and inverter manufacturer and model, ground mounted vs. roof-mounted systems,

\footnotetext{
${ }^{5}$ For details on the standardization and cleaning process, refer to Barbose et al. (2013).
} 
new construction vs. retrofit systems). After cleaning the module and inverter data, additional information on the technology used in each PV installation was inferred, including whether the modules are building-integrated PV (BIPV, vs. rack-mounted), thin-film PV (vs. crystalline), and Chinese made (vs. non-Chinese made), and whether the PV system uses micro-inverters (vs. central or string inverters). To maximize sample size, certain assumptions were made for some PV system characteristic variables when their value was unknown for specific PV systems. Namely, when the variables were unknown, systems were assumed to be retrofit (rather than new construction), crystalline silicon (rather than thin film), and rack mounted (rather than BIPV).

Various screens were applied to select the data used for the analysis. A key step was to isolate PV systems with locations and installation dates that coincided with the Vote Solar and RSC scores. Outliers were removed by only keeping data for systems with installed prices between $\$ 1.5 / \mathrm{W}$ and $\$ 20 / \mathrm{W}^{6}$ as well as excluding PV systems that are ground mounted, self-installed, or have battery backup. Because the focus of this study is on residential systems, we restricted the sample to PV systems between 1 and $10 \mathrm{~kW}$ in size that were identified as either "residential" or "unknown" for customer segment. Customer-owned PV systems are included in our analysis. However, a large fraction of the residential PV systems installed in the United States in recent years is owned by third parties, with the host customer either leasing or purchasing power from such systems. In these cases, as with the underlying TTS VI dataset, PV systems with reported prices identified as likely to represent an "appraised value" rather than a transaction price paid to the installer were removed from the sample. These are third-party-owned (TPO) systems installed by integrated companies that provide both system financing as well as PV system

\footnotetext{
${ }^{6}$ All price data (in $\$ / \mathrm{W}$ ) were converted to real 2012 dollars and are presented in terms of rated module power output under standard test conditions (DC-STC).
} 
installation, and the reported appraised-value pricing in these instances does not reasonably approximate the actual cost of individual installations. On the other hand, systems that are TPO but not installed by integrated companies were retained in the dataset, because the reported prices in these instances reflect the transaction price between the third-party company and the local installer. ${ }^{7}$

In addition to the existing data within the TTS VI dataset, we constructed data fields to be used as control variables in the analysis, leveraging the larger LBNL project mentioned earlier. ${ }^{8}$ Using the zip code data for each PV system installation and data from the U.S. Census Bureau, a number of demographic and socioeconomic characteristics were associated with each PV installation, including household education level, average income and average housing prices in the given zip code, and average household density in the given county. We derived a countylevel composite labor-cost index from average administrative, electrician, and roofing wages using data from the Bureau of Labor Statistics. Cleaning the installer names for each PV installation in our dataset also enabled us to calculate a number of variables that reflect installer experience and competition within counties. These include a discounted county-level installer experience variable, a discounted county-level aggregate experience variable, a county-level installer density variable, a county-level installer market share variable, and a county-level Herfindahl-Hirschman Index (HHI) that measures the degree of concentration of installers in each local PV market (see also Table 5). Finally, we constructed a variable reflecting the net present value of the economic benefits of each PV system, including utility bill savings, based on

\footnotetext{
${ }^{7}$ See Barbose et al. (2013) for additional details on price reporting for TPO systems.

${ }^{8}$ Further details on these variables and their precise construction, beyond what is provided below and in Table 5 , can be found in a forthcoming LBNL report that explores, more broadly, the drivers of PV price variability.
} 
electricity rates and insolation levels (for net-metered systems) as well as the expected present value of any performance-based incentives, feed-in tariffs, solar renewable energy certificate (SREC) payments, federal and state investment tax credits, and cash rebates.

Figure 1 shows the resulting distribution of PV system prices, focusing on the data used for the Vote Solar and RSC analysis; the figure therefore contains data on PV systems installed in 2011 and 2012 in a subset of states and cities, as described further below. The figure illustrates the significant variation in residential PV prices: within our analysis dataset, average prices are roughly $\$ 6 / \mathrm{W}$, but the overall distribution of prices is wide. The degree to which some of this variation may be attributed to differences in permitting practices and other local regulations is the central question addressed by the present study.

The Vote Solar Project Permit campaign provided our first set of regulatory process scores. Vote Solar worked with the Interstate Renewable Energy Council to develop a set of best practices for municipal permitting to be used for scoring local jurisdictions. As indicated in Table 1, seven of these best practices were scored and weighted to determine jurisdictional performance in solar permitting. A total of 915 jurisdictions in the United States have been scored. The data used by Vote Solar to determine scores were obtained from Clean Power Finance's DOE-funded National Solar Permitting Database (SolarPermit.org), which uses a crowdsourcing methodology to populate and verify information on municipal permitting practices and is continuously updated by more than 1,300 users.

The DOE RSC supplied the second set of local regulatory process scores. The RSC is a competitively awarded funding opportunity created by DOE in 2011 with the goal of eliminating market barriers and reducing soft costs via local and state-level initiatives. The RSC included a 
quantitative tracking of participants' progress across a variety of "action areas" that define the local regulatory environment for PV, including local permitting and interconnection processes, interconnection and net metering standards, financing options, and planning and zoning (Table 2). In particular, the 22 teams participating in the RSC program, representing approximately 50 million people and 154 jurisdictions, provided DOE with responses to a multiple-choice questionnaire regarding the status of the local regulatory environment for PV in each participating jurisdiction. These responses were converted to numerical scores and weighted within each action area, according to the impact that local jurisdictions were likely to have in the context of the award funding (Table 2). ${ }^{9}$ Participants were then given 1 year to enact their strategies for enhancing local solar markets. At the end of the year, participants were once again scored using the same questionnaire to obtain a comparison against initial baseline scores and measure local solar market improvements.

These two sets of scores differ in scope. In particular, the RSC scores encompass a substantially larger array of indicators, including those pertaining to state-level policies and financing options, whereas the Vote Solar scores narrowly focus on a core set of city-level solar permitting best practices.

Though Vote Solar scored 915 cities, 603 cities remained within 11 states after matching the Vote Solar data to the TTS data because of limited coverage in the TTS dataset. The Vote Solar scores used here reflect permitting processes in 2013. To match Vote Solar scores with TTS data, which only extend through 2012, we assumed that PV installations in 2012 were reasonably

\footnotetext{
${ }^{9}$ Participants were not made aware of the particular weighting for each response to avoid potential score manipulation.
} 
reflective of permitting procedures that existed in $2013 .{ }^{10}$ In total, 43,551 residential PV $(\leq 10$ $\mathrm{kW}$ ) installations match the Vote Solar data - representing more than 50\% of the residential PV systems installed in the United States in 2012 (SEIA/GTM, 2013). Vote Solar scores range from 0 (least-favorable permitting processes) to 8.5 (most-favorable permitting processes), with an average of 3.1 (Figure 2). Table 3 shows state-level summary statistics for the Vote Solar scores and matched TTS PV prices. The full dataset is dominated by systems and cities in California but also has a significant number of observations in a geographically diverse set of other states.

The DOE RSC program scored 154 jurisdictions; after matching with the TTS installation data, however, 73 cities in six states remained for analysis. Two sets of scores are available: the baseline scores from early 2011 and the final scores from late 2012. To loosely match these scoring time frames, we matched PV installations in 2011 with the 2011 baseline RSC scores, and we matched PV installations from May through December of 2012 with the 2012 final RSC scores. ${ }^{11}$ In total, 13,904 residential PV $(\leq 10 \mathrm{~kW})$ installations match the RSC scoring data. RSC scores range from 228 (least favorable local procedures) to 914 (most-favorable local procedures), with an average of 615 in 2011 and 751 in 2012 (see Figure 2, which collectively summarizes the scores from both periods). Table 4 shows state-level summary statistics for the

\footnotetext{
${ }^{10}$ There may be some limited bias in this temporal match, because some jurisdictions will have streamlined their permitting procedures between 2012 and 2013. Because 2013 price data were not yet available, however, this matching approach was necessary.

${ }^{11}$ We selected these date ranges to balance two competing difficulties with our data. First, the second round of RSC scoring took place in late 2012 and we therefore wanted to match prices in late 2012 to early 2013 to the $2^{\text {nd }}$ RSC score. Unfortunately, 2013 price data were not yet available. We also wanted to ensure that we had two distinct time periods, i.e., 2011 scores are applied to 2011 prices and late 2012 scores are applied to late 2012 prices. Ultimately, however, we also recognize that these specific decisions are at least somewhat arbitrary. We therefore tested alternative date-matching techniques to assess whether this decision greatly impacted our statistical results: it did not.
} 
RSC scores and matched TTS PV prices. The RSC dataset is also dominated by California, but it has significant numbers of systems in Arizona and Texas.

Our statistical methodology evaluates the influence of local permitting and regulatory processes on installed residential PV prices $(\$ / W)$. The main identifying assumption is that the scoring mechanism - whether RSC or Vote Solar - captures the exogenous variation in local regulatory processes. Our primary regression specification is captured by Equation (1):

$$
P_{i j m d y}=\alpha+\beta_{1} S_{j y}^{k}+\beta_{2} X_{i j t}+\beta_{3} Z_{j y}+\beta_{4} D_{i j m d y}+\gamma m+\theta_{j}+\varepsilon_{i j m d y}
$$

This primary specification regresses the installation price per watt for PV system $i$, in jurisdiction $j$, in month $m$ and year $y$, on day $d\left(P_{i j m d y}\right)$ on jurisdiction $j$ 's score in year $y\left(S_{j y}^{k}\right.$ for $k$ in (Vote Solar, RSC) $)^{12}$. Vote Solar scored each jurisdiction once, while the RSC program scored each jurisdiction twice. Thus, we have a single cross section of data from the Vote Solar program and a two-year panel dataset for the RSC program.

A large number of control variables are also included. First, a set of variables comprising system-level characteristics $\left(D_{i j m d y}\right)$ is included: PV system size; PV system size squared; and dummy variables indicating whether the system was installed as part of a new home, uses BIPV, uses thin-film modules, uses modules manufactured in China, employs micro-inverters, and is TPO. Second, a set of demographic and socioeconomic controls $\left(Z_{j y}\right)$ is included: local average education levels, housing prices, and household income. Third, a set of market characteristics $\left(X_{i j t}\right)$ is included: household density, a labor cost index, individual installer experience at the county level, aggregate installer experience, measures of installer competition and market power, and an estimate of the present value of economic benefits of PV to the customer. ${ }^{13}$ Fourth, a linear time trend in months $(m)$ is employed to control for the overall decrease in PV prices over the study period (2011-2012). Finally, time-invariant jurisdiction- or state-level fixed effects $\left(\theta_{j}\right)$

\footnotetext{
${ }^{12}$ The installation price is observed at the daily level, based on the specific date of system installation.

${ }^{13}$ In this case, $t$ represents the time of observation. Some of these variables were observed daily while others were observed monthly or yearly.
} 
are included in a subset of the models to control for any jurisdiction- or state-level variation in prices not otherwise controlled for by other variables included in the model specification.

A mean zero independently and identically distributed error term $\left(\varepsilon_{i j m d y}\right)$ is included. Huber-

White robust standard errors are reported to limit the impacts of heteroskedasticity. Our primary regression outputs do not report clustered standard errors, but the results of clustering at the jurisdiction and state level are discussed in Section 3.

Each of the control variables is described in Table 5, with the expected signs listed. Summary statistics for these control variables, as well as for PV prices and RSC and Vote Solar scores, are provided in Appendix A.

\section{Results}

We present five regression specifications for the RSC program and three for the Vote Solar program. Our primary specifications use ordinary least squares with jurisdiction-level (RSC) and state-level (Vote Solar and RSC) fixed effects to assess the impact of local permitting and other

regulatory processes on PV prices. ${ }^{14} \mathrm{We}$ also include specifications without fixed effects for both scoring programs. Additionally, because the panel data are highly unbalanced, with far greater numbers of PV installations in some jurisdictions than in others, we show some regression results with sample weighting (i.e., pweight). The purpose of sample weighting is to ensure that all jurisdictions are weighted equally, regardless of the number of PV systems installed; as a result, each observation in jurisdiction $j$ is weighted by the inverse of the number of installations within jurisdiction $j$.

\footnotetext{
${ }^{14}$ Because the Vote Solar program scored each jurisdiction only once, we do not have jurisdiction-level variation in the Vote Solar score and therefore cannot include jurisdiction fixed effects in our Vote Solar estimates.
} 
Across all specifications, the $\mathrm{R}^{2}$ values range between 0.31 and 0.48 , consistent with past literature that has similarly sought to understand PV price heterogeneity in the United States (Dong and Wiser, 2013; Dong et al., 2014; Wiser et al., 2006). Much of the unexplained variation may be explained by system-level conditions for which data are hard to come by, such as different roof conditions and consumers' heterogeneity in willingness-to-pay.

Overall, the results provide evidence that local regulatory and permitting processes have impacted installed PV prices. Our preferred regression specifications for the Vote Solar and RSC scores include state fixed effects and jurisdiction fixed effects, to control for potential timeinvariant and unobservable PV price drivers at the state or jurisdiction level. These preferred specifications are presented in column (2) in Table 6 and in columns (2) and (4) in Table 7. Our results suggest that a 1 point increase in the Vote Solar score is associated with an average $\$ 0.021 / \mathrm{W}$ reduction in residential $\mathrm{PV}$ prices, while a 1 point increase in the $\mathrm{RSC}$ score is associated with a $\$ 0.00093 / \mathrm{W}-\$ 0.00135 / \mathrm{W}$ reduction in residential PV prices.

The results for Vote Solar — using a larger dataset—are more robust. In particular, the exclusion of state-level fixed effects (column 1, Table 6) and the application of sample weighting (column 3, Table 6) do not meaningfully impact the size or statistical significance of the Vote Solar score variable, with a range of just $\$ 0.021 / \mathrm{W}$ to $\$ 0.023 / \mathrm{W}$. The results for the RSC, on the other hand, are significantly impacted by model specification. The exclusion of state- and jurisdiction-level fixed effects (column 1, Table 7), for example, reduces the size of the estimated impact to $\$ 0.0004 / \mathrm{W}$, whereas sample weighting (columns 3 and 5 , Table 7) leads the RSC score variable to lose statistical significance. 


\section{Discussion}

Here we discuss the impact of changes in permitting and local regulatory processes on residential PV installation prices as well as the robustness of our specifications. Focusing for the moment on the more-preferred specifications, Figures 3 and 4 summarize the impact of marginal changes in Vote Solar and RSC scores on average residential PV prices, across the full set of jurisdictions (and scores) in the data. We predict marginal changes in PV prices by multiplying the coefficient on score from model (2) (in Table 6) and models (2) and (4) (in Table 7) for the Vote Solar and RSC programs, respectively, by the observed difference in scores between each jurisdiction, while holding all other control variables constant at their average values.

These predictions indicate that the average price of residential PV systems in the highest scoring Vote Solar jurisdiction, all else being equal, would be approximately $\$ 0.18 / \mathrm{W}$ lower than the average price in the lowest-scoring jurisdiction (Figure 3). This variation across jurisdictions equates to roughly $3 \%$ of average residential PV prices in 2012 . When focusing on the inner $90 \%$ of jurisdiction scores (to remove outlier jurisdictions), the impact range drops to $\$ 0.14 / \mathrm{W}$ $(2.2 \%)$. The size of the predicted impact from the RSC scores is larger, with PV prices from the highest- to lowest-scoring jurisdictions (across both scoring time periods) varying by $\$ 0.64 / \mathrm{W}$ or $\$ 0.93 / \mathrm{W}$, depending on model specification (Figure 4). This variation equates to $10 \%-15 \%$ of average PV prices in 2012, but it is greatly impacted by the lowest- and highest-scoring jurisdictions as indicated in Figure 4. When focusing on the inner $90 \%$ of jurisdiction scores (to remove outlier jurisdictions), the impact range drops to $\$ 0.50 / \mathrm{W}$ or $\$ 0.73 / \mathrm{W}(8 \%-12 \%)$, depending on model specification.

As another intuitive measure of the impact of local permitting and other regulatory processes on PV prices, the average RSC score improved by 163 points in our sample from the baseline score 
to the final score. This average score increase translates to a predicted decline in PV prices of $\$ 0.15-\$ 0.22 / \mathrm{W}(2.5 \%-3.6 \%)$. The total decline in average PV prices from 2011 to 2012 was approximately $\$ 1.16 / \mathrm{W}$ in our sample dataset. Our results therefore suggest that, on average, $13 \%-19 \%$ of the total price change might be attributed to improvements in permitting and other local regulatory processes in participating RSC jurisdictions, equating to $\$ 750-\$ 1,100$ for an average-sized (5-kW) residential PV system.

As expected, the results show that RSC scores appear to drive larger local price variations ( $\$ 0.64-0.93 / \mathrm{W}$; as much as $\$ 3,200-\$ 4,700$ for a typically sized residential system, but $\$ 2,500-$ $\$ 3,700$ when focusing on the inner $90 \%$ of jurisdiction scores) than do Vote Solar scores ( $\$ 0.18 / \mathrm{W}$; as much as $\$ 900$ for a typically sized residential system, but $\$ 700$ when focusing on the inner $90 \%$ of scores). Though the two datasets cover different geographies and the scoring methods are not perfectly comparable, presumably these results are driven, in part, by the fact that the RSC scores embed not only variations in local permitting requirements, but also variations in interconnection procedures, planning and zoning, financing options, and net metering rules; Vote Solar scores, on the other hand, narrowly focus on local permitting procedures. These results suggest that local permitting practices do play a role in explaining PV price differences, but that other local regulatory procedures also play important roles.

The validity of these models is supported by the results for many of the control variables, most of which have coefficients with the expected sign. Specifically, the coefficients on PV system size and size squared consistently show that PV prices decrease as system sizes increase but with diminishing margin returns. Other system-level characteristics also have the predicted impacts on PV prices: systems installed in new construction or with Chinese-manufactured modules have lower prices, whereas BIPV systems and those using micro-inverters have higher prices. Results 
for thin-film modules and TPO systems are mixed, with some specifications suggesting a small price premium and others finding insignificant effects or even the opposite effect. As for the demographic and socioeconomic variables, an increase in average education levels tends to result in lower PV prices, perhaps suggesting that competitive bidding is more common for these customers. Increased average housing values, in many specifications, leads to higher PV prices, whereas household income is found to have inconsistent or statistically insignificant effects, but collinearity among these and other variables is of some concern. The coefficients for the labor cost index and household density variables are in opposition to our expectations, but they may similarly be impacted by collinearity with other variables that are proxies for the cost of living, as found in Dong and Wiser (2013). Among the other market-level characteristics, increases in aggregate- and installer-level experience as well as installer density lead to lower PV prices, as expected. Installer market share tends to have a negative coefficient, further suggesting some economies of scale at the local level. These installer-level results also suggest that reductions in soft costs are passed on to the consumer in the form of lower prices. The HHI variable has an unexpected sign, perhaps suggesting that the impact of local installer scale in reducing prices outweighs market-power considerations. The value-of-solar coefficient tends to have a positive sign, indicating that installers are able to raise $\mathrm{PV}$ prices in those markets that provide higher financial incentives for solar installations. Finally, prices decline with time. ${ }^{15}$

Notwithstanding these findings, other regression specifications suggest a certain level of nuance in the results. In particular, the weighted regressions suggest that a small number of large jurisdictions drive the statistical significance of the coefficient of interest for the RSC results. In

\footnotetext{
${ }^{15}$ Forthcoming work by LBNL will provide a deeper analysis of how these and other variables influence PV prices and price variability.
} 
particular, as shown in columns (3) and (5) in Table 7, the score coefficients in the RSC regressions lose significance when all jurisdictions are weighted equally, i.e., when the influence of small-sample jurisdictions is increased and the influence of large-sample jurisdictions is decreased. ${ }^{16}$ On the other hand, as shown in column (3) in Table 6, the Vote Solar results are not impacted by weighting and so are not unduly influenced by large-sample jurisdictions. The impact of large-sample jurisdictions on the RSC results, but not the Vote Solar results, may simply be a consequence of the larger number of jurisdictions in the Vote Solar sample. Alternatively, these results may be an indication of an unexplained geographically heterogeneous impact of permitting and local regulatory processes on residential PV prices.

We performed a number of other tests to verify the robustness of our results. Each control variable was independently removed to determine whether any individual controls had a disproportionate effect on the outcomes. Though the regression results are not presented in the present study, the coefficient estimates for Vote Solar and RSC scores were robust to the removal of all of the control variables. We also tested the possible inclusion of additional control variables (including registered voter affiliation, land area, and population density) but found that the efficiency gains from including these extra controls were outweighed by the cost of lost observations due to limitations in the underlying data set. We experimented with adding nonlinear time trends (including various polynomial functions and functions that might be associated with "learning-by-doing") and time-based fixed effects, but neither had a significant impact on the variables of interest.

\footnotetext{
${ }^{16}$ This was verified by removing the largest jurisdictions (without weighting), with results similar to the weighting method; removing the smallest jurisdictions did not produce similar results.
} 
Finally, we also ran the same regressions with standard errors clustered at the jurisdiction or state level to control for the potential correlation of unobservables below the jurisdiction or state level. ${ }^{17}$ Though not presented here, controlling for potential correlation within jurisdictions (clustering) reduces the statistical power of the results in all but one of our specifications for each scoring program, suggesting that installations within jurisdictions are affected by unobserved characteristics unique to each jurisdiction.

\section{Conclusions and Policy Implications}

As PV module and other hardware costs have declined in recent years, the relative importance of non-hardware soft costs has grown. Understanding these soft costs—-not just PII, but also installation labor, customer acquisition, financing, and so forth — and developing pathways for their reduction may be central to continued solar market expansion in the United States.

This article has statistically isolated the impacts of a portion of these soft costs, namely city-level permitting and other local regulatory processes, on residential PV prices. We find that variations among and improvements in local regulatory processes can affect residential PV prices. Specifically, variations in local permitting procedures are found to drive differences in average residential PV prices of approximately $\$ 0.18 / \mathrm{W}$ across all jurisdictions in our Vote Solar sample; this is $\$ 0.14 / \mathrm{W}$ when focusing on the inner $90 \%$ of jurisdiction scores. For a typical residential PV installation, this equates to a $\$ 700(2.2 \%)$ difference in system costs between jurisdictions

\footnotetext{
${ }^{17}$ Moulton (1990) showed that standard errors can be underestimated when variables are measured at different levels. In the present work, the dependent variable, price per watt, is measured at the system level, while the independent variable of primary interest (RSC or Vote Solar scores) is measured at the jurisdiction level.
} 
with scores across the middle $90 \%$ of the range (i.e., $5^{\text {th }}$ percentile to $95^{\text {th }}$ percentile). When considering variations not only in permitting practices, but also in other local regulatory procedures, price differences grow to $\$ 0.64-\$ 0.93 / \mathrm{W}$ between the least-favorable and mostfavorable jurisdictions in our RSC sample; this range drops to $\$ 0.50-\$ 0.73 / \mathrm{W}$ when focusing on the inner $90 \%$ of jurisdiction scores. For a typical residential PV installation, this corresponds to a price impact of at least $\$ 2,500(8 \%)$ between jurisdictions with scores across the middle $90 \%$ of the range (i.e., $5^{\text {th }}$ percentile to $95^{\text {th }}$ percentile), demonstrating the magnitude of cost reduction that might be possible from streamlining regulatory regimes.

As with Dong and Wiser (2013), these cross-jurisdiction results add to the previous literature that has sought to quantify the national average impacts of permitting and local procedures on PV prices. In particular, the present results show that estimates of national average impacts can mask the additional variation of impacts among jurisdictions and, therefore, also hide the potential for PV price reductions through streamlining the local procedures in those jurisdictions in which current practices are least-favorable for PV.

These results also suggest that the Vote Solar and RSC scores do measure real variations in permitting and other local regulatory processes. First, the Vote Solar and RSC scores are found to have statistically significant impacts on PV prices. Second, the overall size of the effects is broadly consistent with what one might expect, based in part on previous literature. Third, as anticipated, the results show that RSC scores appear to drive larger overall price variations than the Vote Solar scores. Presumably, this is in part because the RSC scores embed not only variations in local permitting requirements, but also variations in interconnection procedures, planning and zoning, financing options, and net metering rules; Vote Solar scores, on the other hand, narrowly focus on local permitting procedures. 
Especially given the much-higher PV prices seen in the United States relative to other major solar markets internationally, additional research is warranted to explore the impact of local regulatory procedures further. First, it would be helpful to expand the frame of the analysis to explore more broadly the impact of these procedures on the participation of (and competition among) installers in certain jurisdictions (expanding on Tong, 2012) as well as on PV demand in those jurisdictions (expanding on Li and Yi, 2014 and Shrimali and Jenner, 2013). Second, though the present analysis focuses on smaller, residential PV installations, it would be helpful to expand this type of work to price variations among larger, commercial installations. Third, as the RSC continues, it may be useful to evaluate the impact of that specific program by analyzing PV price trends in participating jurisdictions relative to non-participating jurisdictions. Finally, because permitting and other local regulatory processes drive only a small fraction of the overall heterogeneity in PV prices seen in the United States, further research to illuminate the full suite of driving influences would be valuable. Such research is currently being performed by LBNL and its partners-Yale University, University of Wisconsin, and University of Texas at Austin.

\section{Acknowledgements}

The work described in this article was funded by the Office of Energy Efficiency and Renewable Energy (Solar Energy Technologies Office) of the U.S. Department of Energy (DOE) under Contract No. DE-AC02-05CH11231. For reviewing earlier versions of this work or providing valuable input, we would particularly like to thank two anonymous reviewers, as well as Galen Barbose and Ben Hoen (LBNL), Kenneth Gillingham and Hao Deng (Yale University), Gregory Nemet (University of Wisconsin-Madison), Varun Rai (University of Texas, Austin), Hilary Pearson (Sungevity), Sean Milich and James Tong (Clean Power Finance), Kristen Ardani 
(National Renewable Energy Laboratory), and Adam Cohen (DOE). For their support of this work, we also thank Elaine Ulrich, Christina Nichols, Adam Cohen and Minh Le of the U.S. DOE. Of course, the authors are solely responsible for any omissions or errors contained herein. 


\section{References}

Ardani, K., Seif, D., Margolis, R., Morris, J., Davidson, C., Truitt, S., Torbert, R., 2013. Non

Hardware (“Soft") Cost Reduction Roadmap for Residential and Small Commercial Solar

Photovoltaics, 2013-2020. National Renewable Energy Laboratory, Golden, CO.

Baker, E., Fowlie, M., Lemoine, D., Reynolds, S., 2013. The economics of solar electricity. Annual Rev. Resource. Economics 5(1), 387-426.

Barbose, G., Darghouth, N., Weaver, S., Feldman, D., Margolis, R., Wiser, R., 2014. Tracking US photovoltaic system prices 1998-2012: a rapidly changing market. Progress in Photovoltaics. DOI: $10.1002 /$ pip.2482.

Barbose, G., Darghouth, N., Weaver, S., Feldman, D., Margolis, R., Wiser, R., 2013. Tracking the Sun VI: An Historical Summary of the Installed Price of Photovoltaics in the United States from 1998 to 2012. Lawrence Berkeley National Laboratory, Berkeley, CA.

Bazilian, M., Onyeji, I., Liebreich, M., MacGill, I., Chase, J., Shah, J., Gielen, D., Arent, D., Landfear, D., Zhengrong, S., 2013. Re-considering the economics of photovoltaic power. Renewable Energy 53(0), 329-338.

Bolinger, M., Weaver, S., 2013. Utility-Scale Solar 2012: An Empirical Analysis of Project Cost, Performance, and Pricing Trends in the United States. Lawrence Berkeley National Laboratory, Berkeley, CA.

Branker, K., Pathak, M.J.M., Pearce, J.M., 2011. A review of solar photovoltaic levelized cost of electricity. Renewable and Sustainable Energy Reviews 15(9), 4470-4482. 
Brooks, B., 2012. Expedited Permit Process for PV Systems: A Standardized Process for the Review of Small-Scale PV Systems. Solar America Board for Codes and Standards.

Candelise, C., Winskel, M., Gross, R., 2013. The dynamics of solar PV costs and prices as a challenge for technology forecasting. Renewable and Sustainable Energy Reviews 26, 96-107.

Dong, C., Wiser, R., 2013. The impact of city-level permitting processes on residential photovoltaic installation prices and development times: An empirical analysis of solar systems in California cities. Energy Policy 63, 531-542.

Dong, C., Wiser, R., Rai, V. (2014). Incentive Pass-through for Residential Solar Systems in California. Berkeley, CA: Lawrence Berkeley National Laboratory.

Edenhofer, O., Pichs-Madruga, R., Sokona, Y., Seyboth, K., Matschoss, P., Kadner, S., Zwickel, T. et al., eds., 2011. IPCC Special Report on Renewable Energy Sources and Climate Change Mitigation. Cambridge University Press, Cambridge and New York.

EPIA, 2014. Global Market Outlook for Photovoltaics: 2014-2018. European Photovoltaic Industry Association, Brussels.

Friedman, B., Ardani, K., Feldman, D., Citron, R., Margolis, R., Zuboy, J., 2013. Benchmarking Non-Hardware Balance-of-System (Soft) Costs for U.S. Photovoltaic Systems, Using a BottomUp Approach and Installer Survey - Second Edition. National Renewable Energy Laboratory, Golden, CO. 
Hernández-Moro, J., Martínez-Duart, J.M., 2013. Analytical model for solar PV and CSP electricity costs: present LCOE values and their future evolution. Renewable and Sustainable Energy Review 20(0), 119-132.

IPCC, 2014. Climate Change 2014: Mitigation of Climate Change: Working Group III Contribution to the Fifth Assessment Report of the IPCC. Cambridge University Press, Cambridge.

Li, H., Yi, H., 2014. Multilevel governance and deployment of solar PV panels in U.S. cities. Energy Policy 69, 19-27.

Moulton, B.R., 1990. An illustration of a pitfall in estimating the effects of aggregate variables on micro unit. Review of Economics and Statistics 72(2), 334-338.

Schaeffer, G., Alsema, E.A., Seebregts, A., Beurskens, L., de Moor, H., van Sark, W.G.J.H.M., Durstewitz, M., Perrin, M., Boulanger, P., Laukamp, H., Zuccaro, C., 2004. Learning from the sun-Analysis of the use of experience curves for energy policy purposes: The case of photovoltaic power. Final report of the Photex project, ECN-C-04-035. Energy Research Centre of the Netherlands, Petten, Netherlands.

Seel, J., Barbose, G., Wiser, R., 2014. An analysis of residential PV system price differences between the United States and Germany. Energy Policy 69, 216-226.

SEIA/GTM, 2014. U.S. Solar Market Insight Report: 2013 Year-in-Review. GTM Research and Solar Energy Industries Association. 
SEIA/GTM, 2013. U.S. Solar Market Insight Report: 2012 Year-in-Review. GTM Research and Solar Energy Industries Association.

Shrimali, G., Jenner, S., 2013. The impact of state policies on deployment and cost of solar PV in the US: a sector specific empirical analysis. Renewable Energy 60, 679-690.

Stanfield, S., Schroeder, E., Culley, T., 2012. Sharing Success: Emerging Approaches to Efficient Rooftop Solar Permitting. Interstate Renewable Energy Council, Latham, NY.

SunRun, 2011. The Impact of Local Permitting on the Cost of Solar Power. SunRun, San Francisco.

Tong, J, 2012. Nationwide Analysis of Solar Permitting and the Implications for Soft Costs. Clean Power Finance, San Francisco.

Wiser, R., Bolinger, M., Cappers, P., Margolis, R., 2007. Analyzing Historical Cost Trends in California's Market for Customer-Sited Photovoltaics. Progress in Photovoltaics: Research and Applications 15(1), 69-85. 
Figures and Tables

Table 1. Vote Solar Project Permit Best Practices and Scoring Methodology

Table 2. Rooftop Solar Challenge Solar Market Maturity Model and Scoring Methodology

Table 3. Vote Solar Matched Summary Statistics

Table 4. Rooftop Solar Challenge Matched Summary Statistics

Table 5. Control Variable Definitions and Expected Direction of Impacts

Table 6. Regression Results: Vote Solar

Table 7. Regression Results: Rooftop Solar Challenge

Appendix Table 1: Summary Statistics: Vote Solar

Appendix Table 2: Summary Statistics: Rooftop Solar Challenge

Figure 1. Distribution of PV System Prices in the Final Dataset for the Vote Solar and Rooftop Solar Challenge Analysis

Figure 2. Distribution of Vote Solar and Rooftop Solar Challenge Scores by PV Systems in the Matched Datasets

Figure 3. Predicted Relationship between Vote Solar Scores and PV Prices

Figure 4. Predicted Relationship between Rooftop Solar Challenge Scores and PV Prices 
Table 1

\begin{tabular}{|c|c|c|c|c|c|c|}
\hline$\#$ & SolarPermit.org Question & Scoring Metric & $\begin{array}{l}\text { Score }=\text { Best } \\
\text { Practice }\end{array}$ & $\begin{array}{c}\text { Score }=\text { Not } \\
\text { Best Practice }\end{array}$ & Weight & $\begin{array}{l}\text { Final } \\
\text { Score }\end{array}$ \\
\hline 1 & $\begin{array}{l}\text { Is there a solar permitting } \\
\text { checklist }\end{array}$ & $\begin{array}{l}\text { Posts requirements } \\
\text { online? }\end{array}$ & yes & no & 0.05 & 0.5 \\
\hline 2 & Online permit applications & $\begin{array}{l}\text { Allows online } \\
\text { processing? }\end{array}$ & available & no & 0.05 & 0.5 \\
\hline 3 & $\begin{array}{l}\text { Is there an over-the- } \\
\text { counter permit option }\end{array}$ & Fast turn-around time? & yes & no & 0.25 & 2.5 \\
\hline 3 & $\begin{array}{l}\text { Average turn-around time } \\
\text { for residential permit }\end{array}$ & Fast turn-around time? & $\leq 3$ days & $>3$ days & 0.15 & 1.5 \\
\hline 4 & $\begin{array}{l}\text { Permit Fee }=\text { "Flat Rate" } \\
\text { PLUS “\$400 or less" }\end{array}$ & $\begin{array}{l}\text { Reasonable permitting } \\
\text { fees? }\end{array}$ & $\leq \$ 400$ & no & 0.25 & 2.5 \\
\hline 5 & $\begin{array}{l}\text { Licensing for solar } \\
\text { contractors }\end{array}$ & $\begin{array}{l}\text { No community-specific } \\
\text { licenses needed? }\end{array}$ & $\begin{array}{l}\text { Additional } \\
\text { licensing not } \\
\text { required }\end{array}$ & $\begin{array}{l}\text { Additional } \\
\text { licensing } \\
\text { required }\end{array}$ & 0.05 & 0.5 \\
\hline 6 & $\begin{array}{l}\text { Time window for a } \\
\text { scheduled inspection }\end{array}$ & $\begin{array}{l}\text { Offers a narrow } \\
\text { inspection appointment } \\
\text { window? }\end{array}$ & $\leq 2$ hours & $>2$ hours & 0.1 & 1 \\
\hline \multirow[t]{2}{*}{7} & $\begin{array}{l}\text { Number of inspections } \\
\text { required }\end{array}$ & $\begin{array}{l}\text { Eliminates excessive } \\
\text { inspections? }\end{array}$ & 1 inspection & $>1$ inspection & 0.1 & 1 \\
\hline & & & & Total Points: & & 10 \\
\hline
\end{tabular}

Source: http://projectpermit.org/2013/02/06/best-practices/; accessed July 2014. 
Table 2:

\begin{tabular}{|c|c|}
\hline ACTION AREA & POINTS \\
\hline Permitting Process & 460 \\
\hline Application & 110 \\
\hline Information Access & 60 \\
\hline Process Time & 110 \\
\hline Fee & 30 \\
\hline Model Process & 30 \\
\hline Inspection & 80 \\
\hline Communication w/ Utility & 40 \\
\hline Interconnection Process & 110 \\
\hline Application & 40 \\
\hline Information Access & 20 \\
\hline Process Time & 20 \\
\hline Inspection & 30 \\
\hline Interconnection Standard & 100 \\
\hline Net-Metering Standard & 100 \\
\hline Financing Options & 150 \\
\hline $\begin{array}{l}\text { Third-Party Ownership (or } \\
\text { equivalent) }\end{array}$ & 90 \\
\hline Direct Finance Options & 25 \\
\hline Community Solar & 15 \\
\hline Other & 20 \\
\hline Planning and Zoning & 80 \\
\hline Solar Rights and Access & 54 \\
\hline Zoning & 20 \\
\hline New Construction & 6 \\
\hline TOTAL POINTS POSSIBLE & 1,000 \\
\hline
\end{tabular}




\section{Table 3:}

\begin{tabular}{ccccc}
\hline State & $\begin{array}{c}\text { City Score } \\
\text { (mean) }\end{array}$ & $\begin{array}{c}\text { Average Price } \\
\text { (\$/watt) }\end{array}$ & $\begin{array}{c}\text { Number of Matched } \\
\text { Vote Solar Cities }\end{array}$ & $\begin{array}{c}\text { Number of } \\
\text { Installations }\end{array}$ \\
\hline Arkansas & 0.0 & 7.07 & 1 & 3 \\
Arizona & 3.2 & 5.24 & 40 & 5,654 \\
California & 3.4 & 6.32 & 318 & 32,472 \\
Connecticut & 2.9 & 6.53 & 8 & 52 \\
Massachusetts & 1.5 & 5.78 & 37 & 533 \\
New Jersey & 1.5 & 5.61 & 72 & 1,662 \\
New Mexico & 0.8 & 6.01 & 3 & 171 \\
New York & 2.5 & 6.33 & 54 & 542 \\
Oregon & 4.0 & 5.82 & 13 & 963 \\
Pennsylvania & 1.5 & 5.89 & 45 & 550 \\
Texas & 0.8 & 4.71 & 12 & 949 \\
Total & & & 603 & $\mathbf{4 3 , 5 5 1}$ \\
& & & &
\end{tabular}

\section{Table 4:}

\begin{tabular}{|c|c|c|c|c|}
\hline State & $\begin{array}{l}\text { Jurisdiction } \\
\text { Score (mean) }\end{array}$ & $\begin{array}{c}\text { Average Price } \\
\text { (\$/watt) }\end{array}$ & $\begin{array}{l}\text { Number of Matched } \\
\text { RSC Jurisdictions }\end{array}$ & $\begin{array}{l}\text { Number of } \\
\text { Installations }\end{array}$ \\
\hline Arizona & 580 & 5.11 & 8 & 1,543 \\
\hline California & 711 & 6.39 & 47 & 11,487 \\
\hline Massachusetts & 657 & 5.45 & 5 & 95 \\
\hline New York & 557 & 9.07 & 1 & 5 \\
\hline Pennsylvania & 393 & 6.14 & 11 & 53 \\
\hline Texas & 669 & 4.28 & 1 & 721 \\
\hline Total & & & 73 & 13,904 \\
\hline
\end{tabular}




\section{Table 5:}

\begin{tabular}{|c|c|c|}
\hline Variable & Definition & Expected Sign \\
\hline system size & PV system size in watts & Negative \\
\hline system size squared & Square term of system size & Positive \\
\hline new construction & PV installed in new home construction (vs. retrofit on existing home) & Negative \\
\hline BIPV & Building-integrated PV system (vs. not) & Positive \\
\hline thin-film & Thin-film PV module (vs. crystalline silicon) & Either \\
\hline China & China-made PV module (vs. not) & Negative \\
\hline micro-inverter & PV system uses micro-inverter (vs. not) & Positive \\
\hline TPO & Third-party-owned PV system (vs. not) & Either \\
\hline education level & Percent of individuals in zip code with bachelor's education or more & Negative \\
\hline mean house value & Mean home value by zip code & Positive \\
\hline mean income & Mean household income by zip code & Positive \\
\hline household density & $\begin{array}{l}\text { Total number of owner-occupied households per square mile within } \\
\text { county }\end{array}$ & Negative \\
\hline labor cost index & Composite labor cost index in county & Positive \\
\hline installer experience & $\begin{array}{l}\text { County-level installation experience by installer, measured as the } \\
\text { discounted cumulative number of PV systems installed }\end{array}$ & Negative \\
\hline aggregate experience & $\begin{array}{l}\text { County-level aggregate installation experience by all installers, measured } \\
\text { as the discounted cumulative number of PV systems installed }\end{array}$ & Negative \\
\hline installer density & Total number of installers within county in last 6 months per household & Negative \\
\hline installer market share & Market share by installer at county level within last year & Either \\
\hline $\mathrm{HHI}$ & $\begin{array}{l}\text { Herfindahl - Hirschman Index for county-level PV market (installer } \\
\text { concentration indicator) }\end{array}$ & Positive \\
\hline value of solar & Present value of customer-economic benefits of a PV system & Positive \\
\hline time & Linear time trend (also tested other specifications, see below) & Negative \\
\hline
\end{tabular}




\section{Table 6:}

\begin{tabular}{|c|c|c|c|}
\hline & $\begin{array}{c}\text { (1) } \\
\text { Price (\$/W) }\end{array}$ & $\begin{array}{c}(2) \\
\text { Price }(\$ / W)\end{array}$ & $\begin{array}{c}\text { (3) } \\
\text { Price }(\$ / W)\end{array}$ \\
\hline \multirow{2}{*}{ Vote Solar score } & $-0.0208^{* * *}$ & $-0.0209^{* * *}$ & $-0.0231^{* *}$ \\
\hline & $(0.003)$ & $(0.003)$ & $(0.008)$ \\
\hline \multirow{2}{*}{ system size } & $-0.560^{* * *}$ & $-0.564^{* * *}$ & $-0.606^{* * *}$ \\
\hline & $(0.020)$ & $(0.020)$ & $(0.053)$ \\
\hline \multirow{2}{*}{ system size squared } & $0.0343^{* * *}$ & $0.0353^{* * *}$ & $0.0378^{* * *}$ \\
\hline & $(0.002)$ & $(0.002)$ & $(0.004)$ \\
\hline \multirow{2}{*}{ new construction } & $-0.548^{* * *}$ & $-0.517^{* * *}$ & $-0.517^{* * *}$ \\
\hline & $(0.046)$ & $(0.047)$ & $(0.097)$ \\
\hline \multirow{2}{*}{ BIPV } & $0.758^{* * *}$ & $0.840^{* * *}$ & $1.033^{* * *}$ \\
\hline & $(0.070)$ & $(0.071)$ & $(0.214)$ \\
\hline \multirow{2}{*}{ thin film } & 0.340 & $0.397^{*}$ & 0.275 \\
\hline & $(0.178)$ & $(0.174)$ & $(0.210)$ \\
\hline \multirow{2}{*}{ China } & $-0.405^{* * *}$ & $-0.429^{* * *}$ & $-0.522^{* * *}$ \\
\hline & $(0.015)$ & $(0.015)$ & $(0.035)$ \\
\hline \multirow{2}{*}{ micro-inverter } & $0.627^{* * *}$ & $0.597^{* * *}$ & $0.326^{* * *}$ \\
\hline & (0.019) & (0.019) & $(0.041)$ \\
\hline \multirow{2}{*}{ TPO } & $0.330^{* * *}$ & -0.0203 & $-0.189^{* * *}$ \\
\hline & $(0.021)$ & $(0.025)$ & $(0.053)$ \\
\hline \multirow{2}{*}{ education level } & $-0.989^{* * *}$ & -0.0879 & -0.0461 \\
\hline & $(0.068)$ & $(0.070)$ & $(0.171)$ \\
\hline \multirow{2}{*}{ mean house value } & $0.00109^{* * *}$ & 0.00000867 & -0.000266 \\
\hline & $(0.000)$ & $(0.000)$ & $(0.000)$ \\
\hline \multirow{2}{*}{ mean income } & -0.000258 & 0.000669 & 0.00154 \\
\hline & $(0.000)$ & $(0.000)$ & $(0.001)$ \\
\hline \multirow{2}{*}{ household density } & $1.148^{* * *}$ & $1.169^{* * *}$ & $1.317^{* * *}$ \\
\hline & $(0.053)$ & $(0.053)$ & $(0.173)$ \\
\hline \multirow{2}{*}{ labor cost index } & $-0.0130^{* * *}$ & $-0.0125^{* * *}$ & -0.00178 \\
\hline & $(0.001)$ & $(0.001)$ & $(0.002)$ \\
\hline \multirow{2}{*}{ installer experience } & $-0.000212^{* * *}$ & $-0.000295^{* * *}$ & -0.0000303 \\
\hline & $(0.000)$ & $(0.000)$ & $(0.000)$ \\
\hline \multirow{2}{*}{ aggregate experience } & $-91.67^{* * *}$ & $-63.15^{* * *}$ & -3.028 \\
\hline & (6.357) & (6.848) & $(15.274)$ \\
\hline \multirow{2}{*}{ installer density } & $-1.034^{* * *}$ & $-1.494^{* * *}$ & $-0.609^{* *}$ \\
\hline & (0.098) & $(0.101)$ & $(0.201)$ \\
\hline \multirow{2}{*}{ installer market share } & -0.0938 & -0.129 & $-0.415^{*}$ \\
\hline & $(0.083)$ & $(0.079)$ & $(0.190)$ \\
\hline \multirow{2}{*}{$\mathrm{HHI}$} & $-1.001^{* * *}$ & $-0.292^{*}$ & -0.219 \\
\hline & (0.099) & $(0.122)$ & $(0.281)$ \\
\hline \multirow{2}{*}{ value of solar } & $0.204^{* * *}$ & $0.0421^{* * *}$ & -0.0297 \\
\hline & (0.009) & $(0.011)$ & $(0.022)$ \\
\hline \multirow{2}{*}{ time } & $-0.0743^{* * *}$ & $-0.0882^{* * *}$ & $-0.102^{* * *}$ \\
\hline & $(0.002)$ & $(0.002)$ & $(0.004)$ \\
\hline pweight & & & yes \\
\hline state fixed effect & & yes & yes \\
\hline $\mathrm{R}^{2}$ & 0.316 & 0.340 & 0.313 \\
\hline $\mathrm{N}$ & 43,551 & 43,551 & 43,551 \\
\hline
\end{tabular}

Robust standard errors in parentheses; ${ }^{*} p<0.05,{ }^{* *} p<0.01,{ }^{* * *} p<0.001$ 
Table 7:

\begin{tabular}{|c|c|c|c|c|c|}
\hline & $\begin{array}{c}(1) \\
\text { Price }(\$ / W)\end{array}$ & $\begin{array}{c}(2) \\
\text { Price }(\$ / W)\end{array}$ & $\begin{array}{c}(3) \\
\text { Price }(\$ / W)\end{array}$ & $\begin{array}{c}(4) \\
\text { Price }(\$ / W) \\
\end{array}$ & $\begin{array}{c}(5) \\
\text { Price }(\$ / W)\end{array}$ \\
\hline \multirow{2}{*}{ RSC score } & $-0.000406^{*}$ & $-0.000930^{* * *}$ & -0.000370 & $-0.00135^{*}$ & 0.000553 \\
\hline & $(0.000)$ & $(0.000)$ & $(0.001)$ & $(0.000)$ & $(0.001)$ \\
\hline \multirow{2}{*}{ system size } & $-0.682^{* * *}$ & $-0.717^{* * *}$ & $-0.545^{* * *}$ & $-0.676^{* * *}$ & $-0.274^{*}$ \\
\hline & $(0.034)$ & $(0.036)$ & (0.069) & $(0.035)$ & $(0.110)$ \\
\hline \multirow{2}{*}{ system size squared } & $0.0451^{* * *}$ & $0.0476^{* * *}$ & $0.0364^{* * *}$ & $0.0449^{* * *}$ & 0.0119 \\
\hline & $(0.003)$ & $(0.003)$ & $(0.006)$ & $(0.003)$ & $(0.010)$ \\
\hline \multirow{2}{*}{ new construction } & $-1.081^{* * *}$ & $-1.171^{* * *}$ & $-0.458^{* * *}$ & $-0.979^{* * *}$ & -0.190 \\
\hline & $(0.083)$ & $(0.092)$ & $(0.137)$ & $(0.085)$ & $(0.148)$ \\
\hline \multirow{2}{*}{ BIPV } & $1.253^{* * *}$ & $1.330^{* * *}$ & $0.771^{* * *}$ & $1.374^{* * *}$ & $0.917^{* * *}$ \\
\hline & $(0.145)$ & $(0.149)$ & $(0.162)$ & $(0.152)$ & $(0.186)$ \\
\hline \multirow{2}{*}{ thin film } & 0.529 & 0.562 & -0.324 & 0.537 & $-0.537^{*}$ \\
\hline & $(0.508)$ & $(0.495)$ & $(0.258)$ & $(0.506)$ & $(0.219)$ \\
\hline \multirow{2}{*}{ China } & $-0.342^{* * *}$ & $-0.359^{* * *}$ & $-0.263^{* * *}$ & $-0.356^{* * *}$ & $-0.218^{*}$ \\
\hline & $(0.028)$ & $(0.028)$ & $(0.065)$ & $(0.028)$ & $(0.086)$ \\
\hline \multirow{2}{*}{ micro-inverter } & $0.496^{* * *}$ & $0.487^{* * *}$ & $0.298^{* * *}$ & $0.507^{* * *}$ & $0.405^{* * *}$ \\
\hline & $(0.034)$ & $(0.033)$ & (0.059) & $(0.034)$ & $(0.077)$ \\
\hline \multirow{2}{*}{ TPO } & $0.328^{* * *}$ & 0.0518 & $0.304^{*}$ & -0.0480 & -0.0431 \\
\hline & $(0.042)$ & $(0.062)$ & $(0.125)$ & $(0.052)$ & $(0.100)$ \\
\hline \multirow{2}{*}{ education level } & $-1.905^{* * *}$ & $-0.422^{* *}$ & -0.666 & $-0.721^{* * *}$ & 0.358 \\
\hline & $(0.126)$ & $(0.163)$ & $(0.440)$ & $(0.138)$ & $(0.389)$ \\
\hline \multirow{2}{*}{ mean house value } & $0.00190^{* * *}$ & $0.000462^{*}$ & 0.000768 & $0.000474^{* *}$ & -0.000219 \\
\hline & $(0.000)$ & $(0.000)$ & $(0.001)$ & $(0.000)$ & $(0.000)$ \\
\hline \multirow{2}{*}{ mean income } & -0.000786 & 0.000314 & 0.00236 & 0.000533 & -0.000957 \\
\hline & $(0.001)$ & $(0.001)$ & $(0.002)$ & $(0.001)$ & $(0.002)$ \\
\hline \multirow{2}{*}{ household density } & $1.655^{* * *}$ & $11.25^{* *}$ & 1.065 & $0.655^{* * *}$ & $1.244^{* *}$ \\
\hline & $(0.145)$ & $(4.132)$ & $(4.414)$ & $(0.155)$ & $(0.393)$ \\
\hline \multirow{2}{*}{ labor cost index } & $-0.0254^{* * *}$ & $-0.0969^{* * *}$ & $-0.0465^{*}$ & $-0.00670^{*}$ & -0.00555 \\
\hline & $(0.003)$ & $(0.011)$ & $(0.020)$ & $(0.003)$ & $(0.006)$ \\
\hline \multirow{2}{*}{ installer experience } & $-0.0000918^{*}$ & $-0.000413^{* * *}$ & -0.0000494 & $-0.000287^{* * *}$ & -0.000358 \\
\hline & $(0.000)$ & $(0.000)$ & $(0.000)$ & $(0.000)$ & $(0.000)$ \\
\hline \multirow{2}{*}{ aggregate experience } & $-221.6^{* * *}$ & $-181.0^{* * *}$ & $-165.3^{*}$ & $-154.6^{* * *}$ & -39.56 \\
\hline & (13.281) & $(40.052)$ & (69.419) & $(14.657)$ & $(35.726)$ \\
\hline \multirow{2}{*}{ installer density } & $-0.486^{* *}$ & 0.978 & -0.729 & $-0.727^{* * *}$ & $-1.406^{* *}$ \\
\hline & $(0.187)$ & $(0.503)$ & $(0.902)$ & $(0.182)$ & $(0.515)$ \\
\hline \multirow{2}{*}{ installer market share } & $-1.355^{* * *}$ & -0.287 & $-2.748^{* * *}$ & $-0.635^{* *}$ & -0.121 \\
\hline & $(0.193)$ & $(0.207)$ & $(0.662)$ & $(0.206)$ & $(0.960)$ \\
\hline \multirow{2}{*}{$\mathrm{HHI}$} & $-5.982^{* * *}$ & -0.769 & -1.316 & $-1.713^{* * *}$ & 0.101 \\
\hline & $(0.451)$ & $(0.916)$ & $(1.631)$ & $(0.452)$ & $(1.322)$ \\
\hline \multirow{2}{*}{ value of solar } & $0.189^{* * *}$ & $0.108^{* * *}$ & $0.211^{* * *}$ & 0.0187 & 0.0743 \\
\hline & $(0.018)$ & $(0.030)$ & (0.059) & $(0.024)$ & $(0.046)$ \\
\hline \multirow{2}{*}{ time } & $-0.0524^{* * *}$ & $-0.0469^{* * *}$ & $-0.0495^{* * *}$ & $-0.0684^{* * *}$ & $-0.0706^{* * *}$ \\
\hline & $(0.003)$ & $(0.004)$ & $(0.010)$ & $(0.003)$ & $(0.008)$ \\
\hline pweight & & & yes & & yes \\
\hline state fixed effect & & & & yes & yes \\
\hline Jurisdiction fixed effect & & yes & yes & & \\
\hline
\end{tabular}




\begin{tabular}{lccccc}
$\mathrm{R}^{2}$ & 0.382 & 0.422 & 0.475 & 0.398 & 0.371 \\
$\mathrm{~N}$ & 13,904 & 13,904 & 13,904 & 13,904 & 13,904 \\
\hline Robust standard errors in parentheses; ${ }^{*} p<0.05,{ }^{* * *} p<0.01,{ }^{* * *} p<0.001$ &
\end{tabular}

\section{Appedix_Table 1:}

\begin{tabular}{llllll} 
& mean & s.d. & min & max & count \\
\hline system price (\$/W) & 6.061 & 1.677 & 1.507 & 19.673 & 49,864 \\
Vote Solar score & 3.104 & 2.229 & 0.000 & 8.500 & 49,864 \\
system size & 5.060 & 2.135 & 1.000 & 10.000 & 49,864 \\
system size squared & 30.163 & 23.764 & 1.000 & 100.000 & 49,864 \\
new construction (1=yes, 0=no) & 0.036 & 0.186 & 0.000 & 1.000 & 49,864 \\
BIPV (1=yes, 0=no) & 0.008 & 0.089 & 0.000 & 1.000 & 49,864 \\
thin film (1=yes, 0=no) & 0.004 & 0.062 & 0.000 & 1.000 & 49,864 \\
China (1=yes, 0=no) & 0.270 & 0.444 & 0.000 & 1.000 & 44,295 \\
micro-inverter (1=yes, $0=$ no) & 0.251 & 0.434 & 0.000 & 1.000 & 44,713 \\
TPO (1=yes, 0=no) & 0.405 & 0.491 & 0.000 & 1.000 & 49,864 \\
education level & 0.360 & 0.177 & 0.000 & 0.928 & 49,821 \\
mean house value (thousands) & 462.215 & 219.946 & 61.647 & $1,182.356$ & 49,635 \\
mean income (thousands) & 94.026 & 34.643 & 28.300 & 394.381 & 49,644 \\
household density & 0.098 & 0.163 & 0.000 & 2.837 & 49,819 \\
labor cost index & 57.032 & 14.732 & 25.140 & 110.007 & 49,679 \\
installer experience & 119.388 & 192.868 & 1.000 & $2,142.346$ & 49,864 \\
aggregate experience & 0.003 & 0.001 & 0.000 & 0.009 & 49,819 \\
installer density & 0.152 & 0.096 & 0.000 & 1.479 & 49,822 \\
installer market share & 0.086 & 0.140 & 0.000 & 1.000 & 49,469 \\
HHI & 0.101 & 0.114 & 0.024 & 1.000 & 49,469 \\
value of solar & 6.278 & 1.609 & 1.844 & 14.632 & 49,672
\end{tabular}




\section{Appedix_Table 2:}

\begin{tabular}{|c|c|c|c|c|c|}
\hline & mean & s.d. & $\min$ & $\max$ & count \\
\hline system price $(\$ / \mathrm{W})$ & 6.113 & 1.725 & 1.507 & 19.409 & 16,427 \\
\hline RSC score & 679.462 & 106.504 & 228.000 & 914.000 & 16,427 \\
\hline system size & 4.887 & 2.149 & 1.000 & 10.000 & 16,427 \\
\hline system size squared & 28.497 & 23.108 & 1.000 & 100.000 & 16,427 \\
\hline new construction ( $1=y e s, 0=$ no) & 0.040 & 0.195 & 0.000 & 1.000 & 16,427 \\
\hline BIPV (1=yes, $0=$ no) & 0.005 & 0.071 & 0.000 & 1.000 & 16,427 \\
\hline thin film ( $1=y e s, 0=$ no) & 0.004 & 0.059 & 0.000 & 1.000 & 16,427 \\
\hline China (1=yes, $0=$ no) & 0.261 & 0.439 & 0.000 & 1.000 & 14,055 \\
\hline micro-inverter ( $1=$ yes, $0=$ no) & 0.257 & 0.437 & 0.000 & 1.000 & 14,179 \\
\hline TPO (1=yes, 0=no) & 0.380 & 0.485 & 0.000 & 1.000 & 16,427 \\
\hline education level & 0.386 & 0.183 & 0.000 & 0.913 & 16,407 \\
\hline mean house value (thousands) & 489.143 & 222.126 & 100.071 & $1,160.356$ & 16,391 \\
\hline mean income (thousands) & 95.326 & 36.752 & 29.476 & 320.744 & 16,399 \\
\hline household density & 0.138 & 0.220 & 0.001 & 2.837 & 16,422 \\
\hline labor cost index & 57.562 & 12.300 & 28.130 & 102.270 & 16,422 \\
\hline installer experience & 163.685 & 270.184 & 1.000 & $2,142.346$ & 16,427 \\
\hline aggregate experience & 0.003 & 0.001 & 0.000 & 0.007 & 16,422 \\
\hline installer density & 0.140 & 0.088 & 0.000 & 0.717 & 16,423 \\
\hline installer market share & 0.059 & 0.073 & 0.000 & 0.895 & 16,295 \\
\hline $\mathrm{HHI}$ & 0.071 & 0.041 & 0.024 & 0.943 & 16,295 \\
\hline value of solar & 6.254 & 1.663 & 3.285 & 14.141 & 16,419 \\
\hline
\end{tabular}




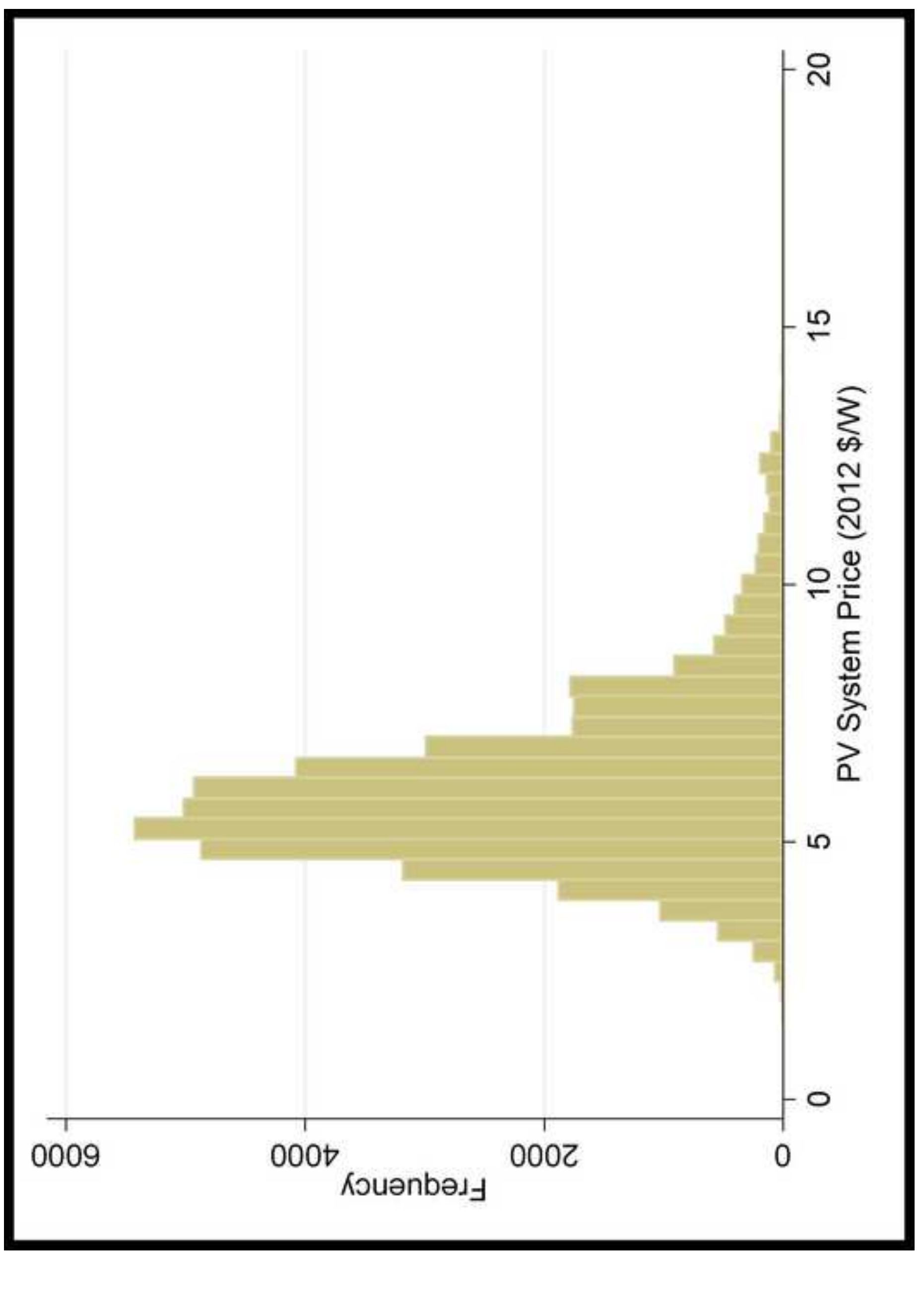




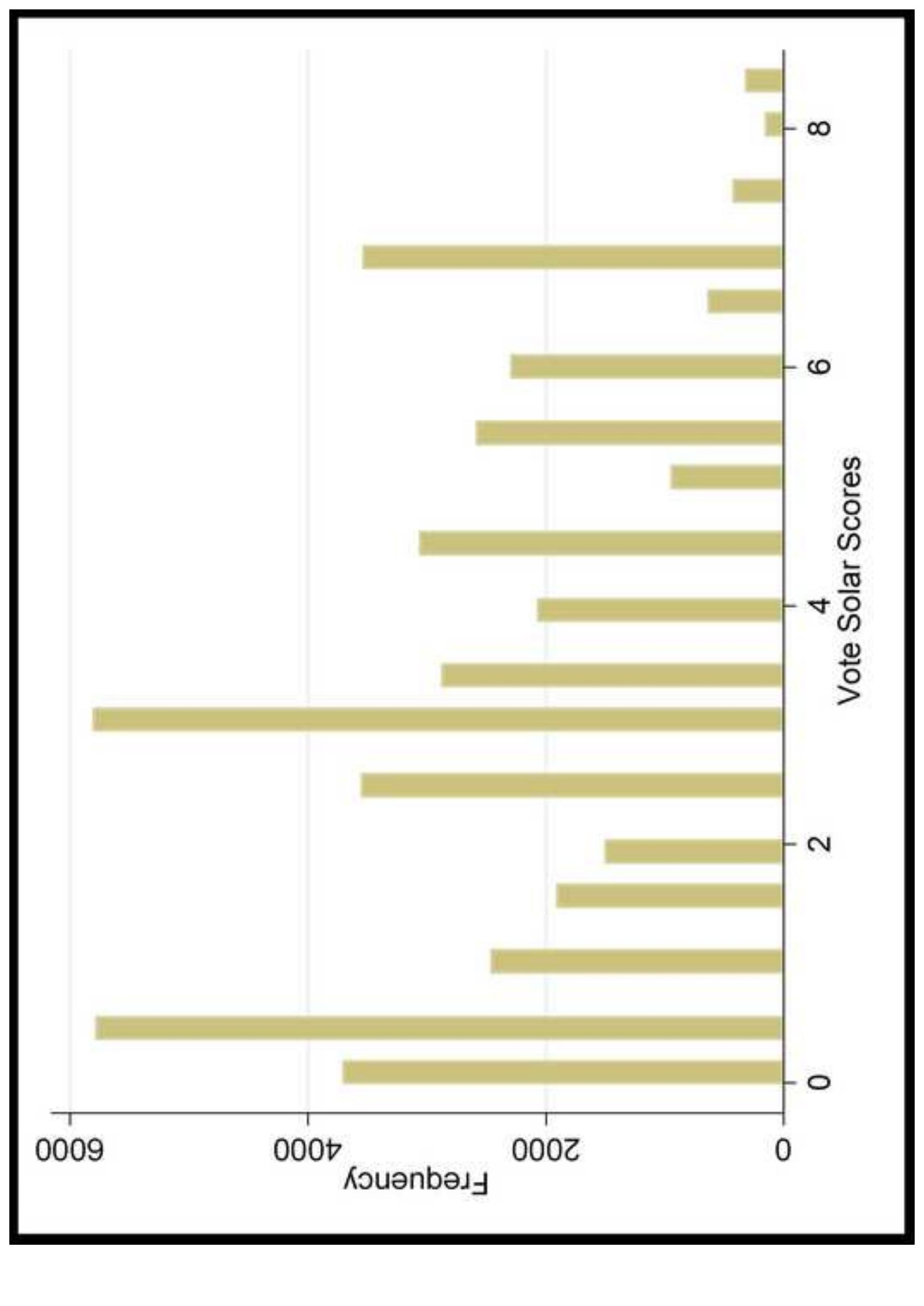




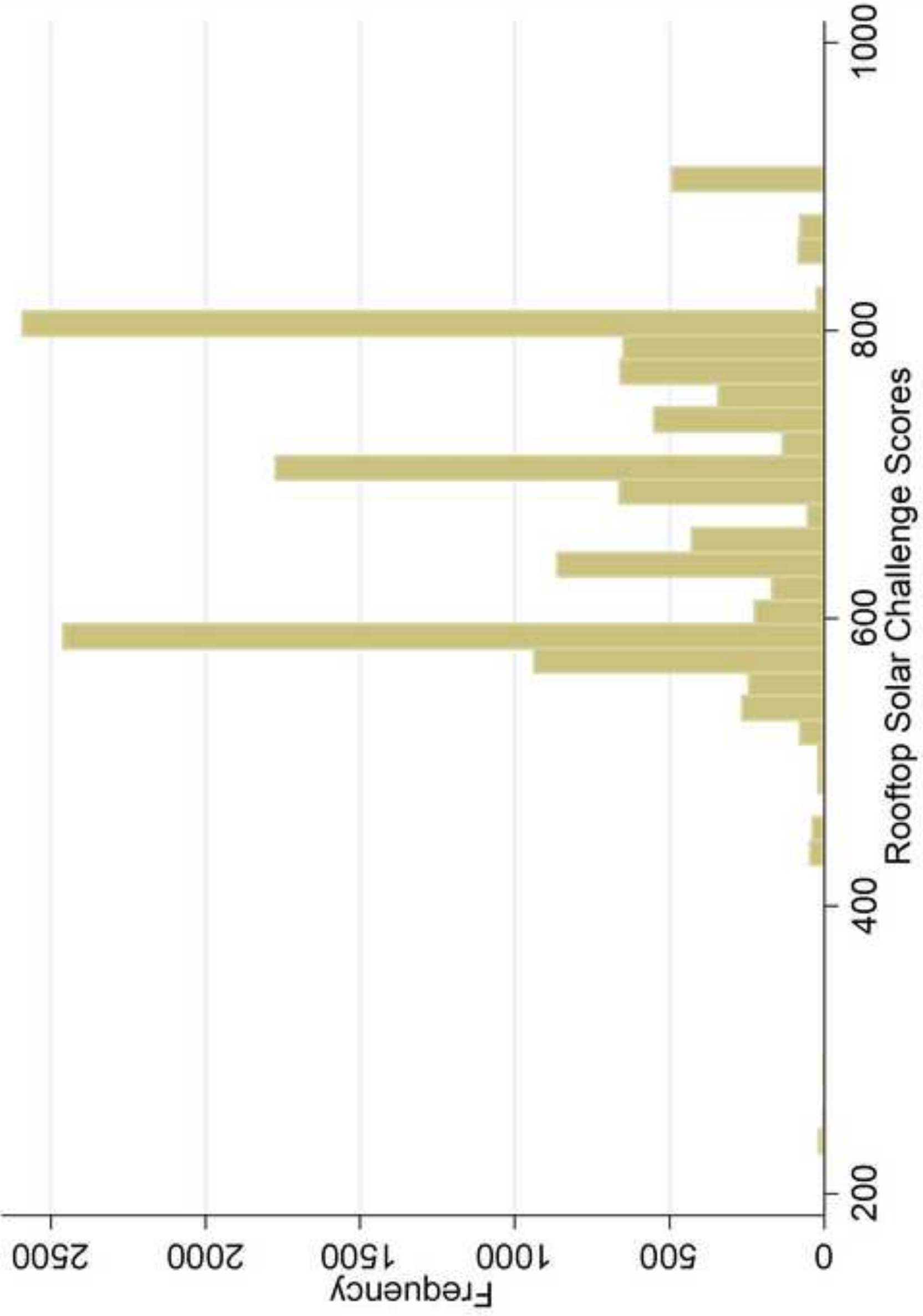




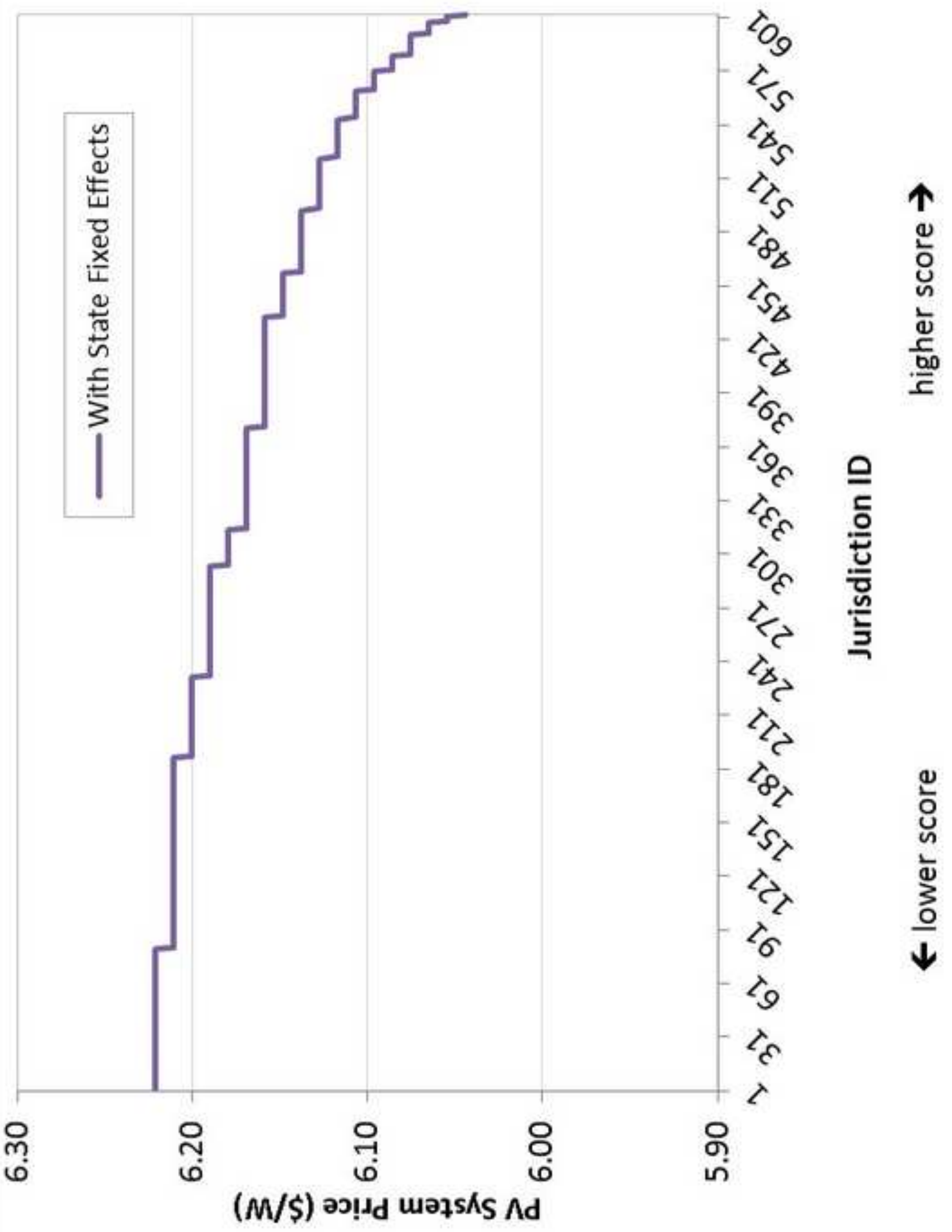




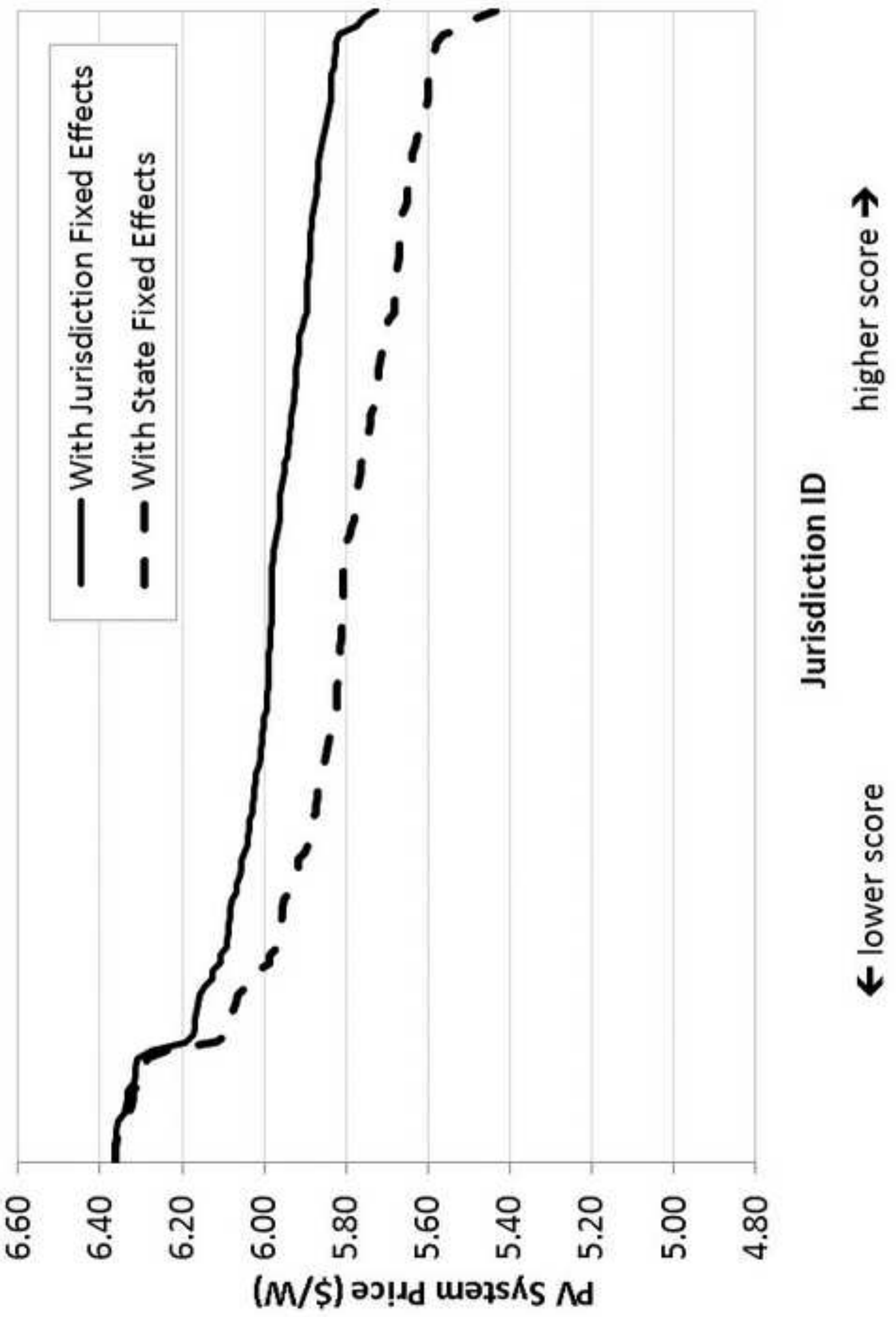

